\title{
ARTHROSCOPIC MANAGEMENT OF SUPERIOR LABRUM ANTERIOR TO POSTERIOR (SLAP) LESIONS
}

\section{El Sayed Abdel-Moaty Mohamed, Mohamed Safwat Moustafa Shalaby, Ali Tawfik El Alfi and Ahmed Hatem Farhan, Orthopedic Department, Zagazig University Hospitals, Egypt.}

\section{ABSTRACT}

Background: Superior labrum anterior to posterior (SLAP) lesions are labral tears that extend anteriorly from the posterior superior labrum, involving the long head of the biceps tendon originating from the glenoid labrum, and stopping before the anterior glenoid notch. Accurate diagnosis of suspected SLAP tears is confirmed by arthroscopy. Progress in arthroscopic techniques had made it possible to achieve accurate and safe repair in selected patterns of injury. Recent outcomes studies have shown good functional results and an acceptable rate of return to activity with treatment of SLAP tears by arthroscopy.

Aim of the work: The aim of this work is to evaluate the diagnosis, clinical outcome and management of superior labrum anterior to posterior (SLAP) lesions using arthroscopy.

Patients and Methods: This is prospective study consisted of twenty denovo patients who had done arthroscopy for the treatment of isolated SLAP lesions between (2011) to (2014). Inclusion Criteria: Adult denovo patients aged from (20-55) years old. All patients provided written informed consent to share in the study. Patients diagnosed by: thorough clinical examination (history, clinical presentation and examination), radiological diagnosis (plain x-ray \& MRI), SLAP lesions that did not respond to non surgical treatment, and lastly SLAP lesions either isolated or associated with other lesions (Bankart lesion \& rotator cuff lesions). Exclusion Criteria: Patients' refusal to share in the study, Frozen shoulder, Failed previous surgery to patient with SLAP lesion.

Results: In our study there was significant difference regarding UCLA score between pre and post operative as in preoperative $100 \%$ UCLA score was <27 Fair/Poor not satisfied, while in postoperative 90\% UCLA score was $>27$ Good/Excellent was satisfied, and only 10\% UCLA was $<27$ Fair/Poor not satisfied.

Conclusion: Treatment of SLAP lesions by arthroscopy is challenging and provides good functional outcome.

Keywords: Superior labrum anterior to posterior lesions, abnormalities of long head of biceps tendon, biceps tenotomy and tenodesis.

Corresponding author: Ahmed Hatem Farhan.

Received : 4 October 2015

Tel: 00201024571716 ,

Accepted: 28 October 2015

\section{INTRODUCTION}

Superior labrum anterior to posterior (SLAP) lesions are labral tears that extend from the posterior superior labrum, involving the long head of the biceps tendon which originates from the glenoid labrum, and stopping before the anterior glenoid notch ${ }^{[1]}$. Lesions of the superior glenoid labrum and biceps anchor are a well known cause of shoulder pain ${ }^{[2]}$. Advances in shoulder arthroscopy have led to improvements in identification and treatment of superior labral anterior-posterior (SLAP) tears ${ }^{[3]}$. Recent biomechanical studies have postulated several theories for the pathogenesis of SLAP tears in throwing athletes and the effect of these injuries on normal shoulder biomechanics ${ }^{[4]}$. Advances in imaging techniques have led to improved accuracy in diagnosing SLAP tears. However, the diagnosis of clinically relevant
SLAP tears remains challenging as there is no specific examination findings and the frequency of associated shoulder lesions ${ }^{[5]}$. Definitive diagnosis of suspected SLAP tears is confirmed during arthroscopic evaluation [6]. Progress in surgical techniques had made it possible to achieve accurate repair in selected types of injury. Recent studies have shown predictably good functional results and an acceptable rate of return to sport and/or work with arthroscopic treatment of SLAP tears ${ }^{[2]}$.

\section{PATIENTS AND METHODS}

Demographics: This is prospective study consisted of twenty denovo patients who had done arthroscopy for treatment of SLAP lesions between March / 2011 to March 12015 .

Inclusion Criteria: (1) Adult denovo patients aged from (20-55) years old, (2) All patients 
provided written informed consent to share in the study, (3) Patients diagnosed by: thorough clinical examination (history, clinical presentation and examination), radiological diagnosis (plain x-ray \& MRI), (4) SLAP lesions that did not respond to non surgical treatment, and (5) lastly SLAP lesions either isolated or associated with other lesions (Bankart lesion \& rotator cuff lesions).

Exclusion Criteria: (1) Patients' refusal to share in the study, (2) Frozen shoulder, (3) Failed previous surgery to patient with SLAP lesion.

Technical Design: The study was conducted in orthopedic department; Faculty of medicine; Zagazig university. Patients were selected from outpatient clinics in Zagazig university hospitals. Sample Size was 20 patients (18 men and 2 women). Among them, 15 patients had at least 12 months of follow up. Average age at operation was 34.05 (20-55) years old (table 1). There were 17 patients in their dominant arm (13 were right and 4 were left dominant arms) and 3 patients in their non dominant left arm (figure $1,2,3)$. The mean duration from the time of injury to arthroscopic treatment was 18 months (12-24) months, and mean follow up period was 18 months (12-24) Months (table 2). Preoperative assessment was done on the day before operation, and informed consent was taken from all patients. Treatment based on the type of SLAP lesion and age of the patient.

Table (1): Includes patients' age, sex, type of SLAP lesion, associated lesions, mechanism of injury, affected arm and follow up period.

\begin{tabular}{llllllll}
\hline $\begin{array}{l}\text { Case } \\
\text { No }\end{array}$ & Age & Sex & $\begin{array}{l}\text { SLAP } \\
\text { type }\end{array}$ & $\begin{array}{l}\text { Associated } \\
\text { lesions }\end{array}$ & $\begin{array}{l}\text { Mechanism of } \\
\text { injury }\end{array}$ & $\begin{array}{l}\text { Dominant } \\
\text { R/L arm }\end{array}$ & $\begin{array}{l}\text { Follow } \\
\text { up }\end{array}$ \\
\hline 1 & 22 & Male & I & Isolated & Compression & D Right & $12 \mathrm{M}$ \\
\hline 2 & 55 & M & I & Partial R.C tear & Traction & D Right & $12 \mathrm{M}$ \\
\hline 3 & 30 & M & II & Isolated & Throwing & D RIGHT & $12 \mathrm{M}$ \\
\hline 4 & 42 & M & II & Isolated & Compression & D LEFT & $12 \mathrm{M}$ \\
\hline 5 & 50 & M & III & Isolated & Traction & D RIGHT & $18 \mathrm{M}$ \\
\hline 6 & 26 & M & II & Isolated & Compression & D LEFT & $12 \mathrm{M}$ \\
\hline 7 & 30 & F & II & Isolated & Throwing & D RIGHT & $12 \mathrm{M}$ \\
\hline 8 & 34 & M & II & Bankart & Throwing & D LEFT & $24 \mathrm{M}$ \\
\hline 9 & 28 & M & I & Partial R.C tear & Compression & Non D & $12 \mathrm{M}$ \\
& & & & & & LEFT & \\
\hline 10 & 54 & M & IV & Isolated & Traction & D RIGHT & $12 \mathrm{M}$ \\
\hline 11 & 33 & M & II & Partial R.C tear & Throwing & D RIGHT & $12 \mathrm{M}$ \\
\hline 12 & 26 & M & III & Isolated & Throwing & D RIGHT & $12 \mathrm{M}$ \\
\hline 13 & 20 & F & III & Partial R.C tear & Traction & Non D & $24 \mathrm{M}$ \\
& & & & & & LEFT & \\
\hline 14 & 23 & M & II & Bankart & Traction & D LEFT & $12 \mathrm{M}$ \\
\hline 15 & 37 & M & II & Impingement & Both & D RIGHT & $12 \mathrm{M}$ \\
\hline 16 & 44 & M & III & Bankart & Both & D RIGHT & $12 \mathrm{M}$ \\
\hline 17 & 35 & M & III & Bankart & Compression & D RIGHT & $18 \mathrm{M}$ \\
\hline 18 & 41 & M & II & Partial R.C tear & Traction & D RIGHT & $12 \mathrm{M}$ \\
\hline 19 & 27 & M & IV & Isolated & Compression & Non D & $12 \mathrm{M}$ \\
& & & & & LEFT & $18 \mathrm{M}$ \\
\hline 20 & 24 & M & II & Isolated & Compression & D RIGHT \\
\hline & & & & & & & \\
\hline
\end{tabular}


Table (2): Shows Patients characteristics and distribution in studied patients.

\section{Frequency Percent}

\begin{tabular}{|c|c|c|c|}
\hline \multirow[t]{2}{*}{$\overline{\text { SEX }}$} & $\mathbf{F}$ & 2 & $\overline{10.0}$ \\
\hline & $\overline{\mathbf{M}}$ & 18 & 90.0 \\
\hline \multirow{4}{*}{ SLAP } & $\mathbf{I}$ & 3 & $\mathbf{1 5 . 0}$ \\
\hline & II & 10 & 50.0 \\
\hline & III & 5 & 25.0 \\
\hline & IV & 2 & $\mathbf{1 0 . 0}$ \\
\hline \multirow{4}{*}{ Mechanism } & Combined & 2 & 10.0 \\
\hline & Compression & 7 & 35.0 \\
\hline & Throwing & 5 & 25.0 \\
\hline & Traction & 6 & 30.0 \\
\hline \multirow{3}{*}{ Dominant Arm } & Dominant Left & 4 & 20.0 \\
\hline & Dominant Right & 13 & 65.0 \\
\hline & Non Dominant Left & 3 & 15.0 \\
\hline \multirow{3}{*}{$\begin{array}{l}\text { Duration from onset of } \\
\text { symptoms till treatment }\end{array}$} & $12 \mathrm{M}$ & 15 & 75.0 \\
\hline & $18 \mathrm{M}$ & 3 & 15.0 \\
\hline & $24 \mathrm{M}$ & 2 & 10.0 \\
\hline Total & - & 20 & 100 \\
\hline
\end{tabular}

Pie diagram for sex distribution:

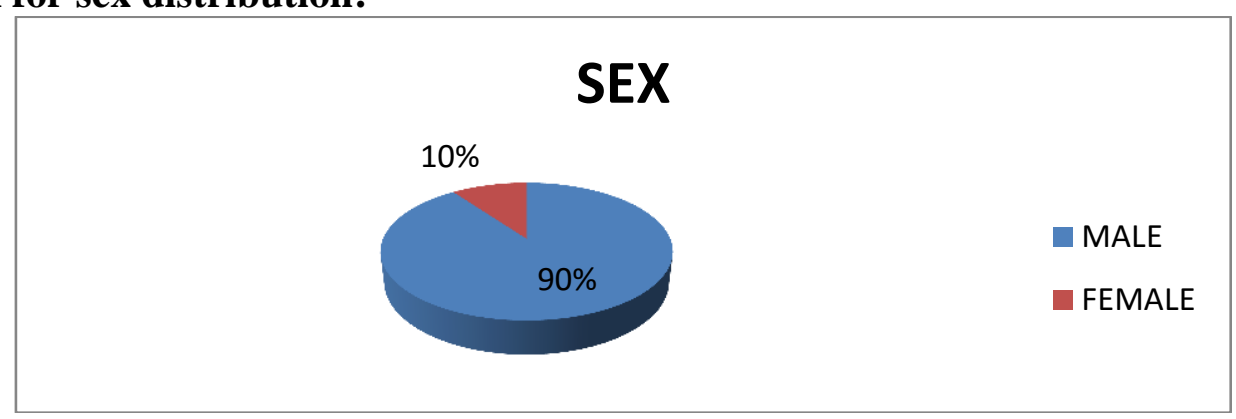

Figure (1): This diagram shows that $90 \%$ of patients were male while $10 \%$ was female.

Pie diagram for dominant arm distribution: 


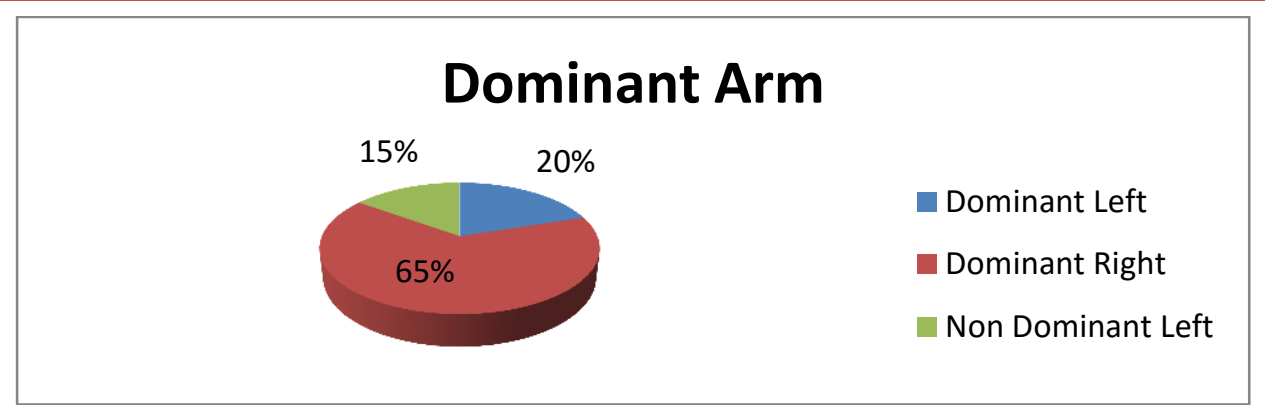

Figure (2): This diagram shows that $65 \%$ of patients with dominant right arm, $20 \%$ with dominant left arm, $15 \%$ with non dominant left arm.

Pie diagram for mechanism of injury distribution:

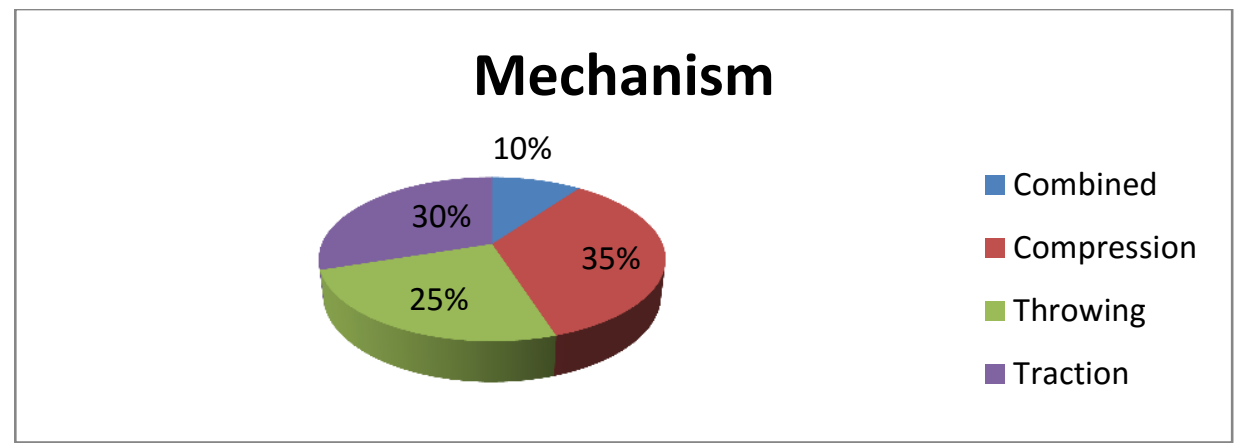

Figure (3): This diagram shows that $35 \%$ of patients with compression injury, $30 \%$ with traction injury, $25 \%$ with throwing injury and $10 \%$ with combined injury.

\section{Preoperative Evaluation of SLAP Lesion:}

I- Thorough Clinical evaluation: (History, Clinical presentation and clinical examination). II- Radiological diagnosis: Plain X-Ray and MRI (figure 4, 5).

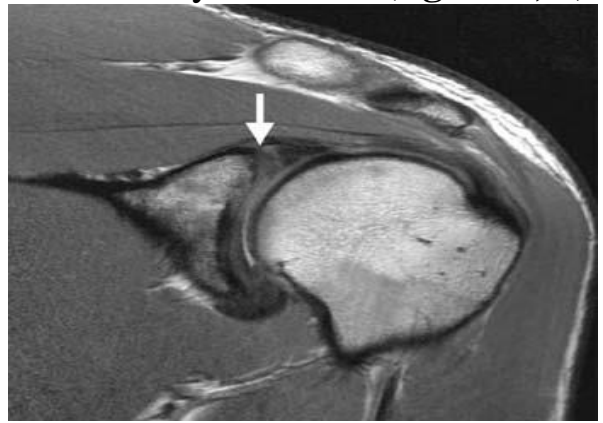

Figure (4): Coronal view of a non contrast magnetic resonance imaging (MRI) demonstrating type II SLAP lesion (white arrow).

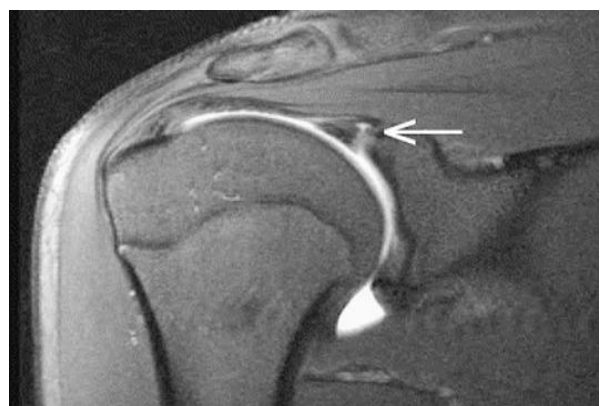

Figure (5): T2 weighted, coronal oblique MRI image demonstrating SLAP lesion. Note the extension of joint fluid into the irregular cleft of the superior labral tear (arrow).

The criteria for diagnosis of SLAP lesions are: history of overuse or trauma, click or pain in the Superior area of the shoulder, active compression test or compression rotation test is positive 
and MRI findings are Positive. The indication for operation was if the patients have at least three criteria (table 3).

The decision making for arthroscopic treatment of SLAP lesion depends on several factors, they include type of SLAP lesion, age of the patient, activity of the patient and associated lesions.

Table (3): Preoperative data of patients with SLAP Lesion.

\begin{tabular}{|c|c|c|c|c|}
\hline $\begin{array}{l}\text { Case } \\
\text { No. }\end{array}$ & History & Symptoms & Signs & MRI \\
\hline 1 & $\begin{array}{l}\text { Compression } \\
\text { Injury }\end{array}$ & Pain with lifting & $\begin{array}{l}\text { Positive active } \\
\text { compression } \\
\text { test (PACT). }\end{array}$ & Positive \\
\hline 2 & Traction & Pain with lifting & (PACT). & Positive \\
\hline 3 & Throwing & Pain with throwing & (PACT). & Negative \\
\hline 4 & Compression & Pain with lifting & (PACT). & Positive \\
\hline 5 & Traction & Pain with lifting & (PACT). & Negative \\
\hline 6 & Compression & Pain with lifting & (PACT). & Positive \\
\hline 7 & Throwing & Pain with throwing & (PACT). & Negative \\
\hline 8 & Throwing & $\begin{array}{l}\text { Pain with throwing \& } \\
\text { Click }\end{array}$ & (PACT). & Negative \\
\hline 9 & Compression & Pain with lifting & (PACT). & Positive \\
\hline 10 & Traction & Pain with lifting & (PACT). & Positive \\
\hline 11 & Throwing & Pain with throwing & (PACT). & Negative \\
\hline 12 & Throwing & Pain with throwing & (PACT). & Positive \\
\hline 13 & Traction & Pain with lifting & (PACT). & Positive \\
\hline 14 & Traction & Pain with lifting \& Click & (PACT). & Positive \\
\hline 15 & Both & Pain with activity & (PACT). & Negative \\
\hline 16 & Both & $\begin{array}{l}\text { Pain with activity \& } \\
\text { Click }\end{array}$ & (PACT). & Positive \\
\hline 17 & Compression & Pain with lifting \& Click & (PACT). & Negative \\
\hline 18 & Traction & Pain with lifting & $(\mathrm{PACT})$ & Negative \\
\hline 19 & Compression & Pain with lifting & (PACT). & Positive \\
\hline 20 & Compression & Pain with lifting & (PACT). & Positive \\
\hline
\end{tabular}

\section{SURGICAL PROCEDURES}

The patient is anesthetized under general anesthesia. Complete examination under anesthesia of the involved and contralateral shoulder. The total arc of motion and deficits in internal rotation in the symptomatic shoulder should be noted. Subtle instability or increased anterior translation may be present. Shoulder arthroscopy was done with the patient in the beach chair position. Using a $30^{\circ}$ arthroscope is introduced into the glenohumeral joint via the posterior soft-spot portal. Then, a standard anterior portal is established in the rotator cuff interval lateral to coracoid process and a complete diagnostic arthroscopy is performed.
- After a complete clinical examination under anesthesia is performed, we perform shoulder arthroscopy under complete aseptic conditions with the patient in the beach chair position. We prefer to support the neck using hard neck collar in this postion. The surgeons stand on the same operating limb while the monitor is in the opposite side infront of the surgeons and the fluid supply is proximally beside the head of the patient.

- Using a $30^{\circ}$ arthroscope is introduced into the glenohumeral joint via the posterior soft-spot portal which is located $2 \mathrm{Cm}$ inferiorly and 1 $\mathrm{Cm}$ medially to the posterolateral corner of the acromion process. Then, a standard anterior portal which is located lateral to the 
coracoid process is established in the rotator cuff interval and a complete diagnostic arthroscopy is performed..

- A thorough arthroscopic evaluation of the glenohumeral joint and subacromial space is necessary to complete our assessment.

- There were 3 cases in this study which had SLAP lesion type I, in which the torn and frayed labral tissue was debrided with preservation of the attachment of the labrum and biceps tendon to the glenoid. One case was isolated so did not need further treatment while 2 cases were associated with partial rotator cuff tear so we did also, subacromial decompression, acromioplasty and repair of rotator cuff tear by one knotted suture anchor through subacromial space (table 4).

- There were 10 cases in this study which had SLAP lesion type II and the patients were managed according to age and arthroscopic features of SLAP lesion and associated lesions. There were 5 cases with isolated SLAP II and were treated by repair and refixation of the superior anterior labrum by suture anchor (one was knotless anchor and 4 were knotted anchor). There were 2 cases associated with partial rotator cuff tear that were treated by repair and refixation of the anterosuperior labrum by one knotted suture anchor plus subacromial decompression, acromioplasty and repair of rotator cuff tear by one knotted suture anchor through subacromial space. There were 2 cases associated with Bankart lesion that were treared by repair and refixation of the anteroinferior labrum (Bankart lesion) by 2 knotted suture anchor plus repair and refixation of the superior anterior labrum by one knotted suture anchor. There was one case associated with rotator cuff impingement and was treated by repair and refixation of the anterosuperior labrum by one knotted suture anchor plus subacromial decompression, acromioplasty through subacromial space (table 4).

- There were 5 cases in this study which had SLAP lesion type III, who were treated with excision of the bucket handle portion of the tear. There were 2 cases with isolated lesion that were treated after excision of the bucket handle tear one case by biceps tenotomy for the patient whose age was 50 years old and another case by refixation of the anterosuperior labrum by one knotted suture anchor. There were 2 cases associated with Bankart lesion that were treared after excision of the bucket handle tear by repair and refixation of the anteroinferior labrum (Bankart lesion) by 2 knotted suture anchor plus repair and refixation of the anterosuperior labrum by one knotted suture anchor. There was one case associated with partial rotator cuff tear that was treated treated after excision of the bucket handle tear by repair and refixation of the anterosuperior labrum by one knotted suture anchor plus subacromial decompression, acromioplasty and repair of rotator cuff tear by one knotted suture anchor through subacromial space (table 4).

- There were 2 cases in this study which had SLAP lesion type IV who were treated with excision of the torn labrum with debridement of the superior labrum then one cases was treated by biceps tenotomy (/the patient age was 54 years old) and another case was treated by biceps tenodesis (age was 27 years old) (table 4). 
Table (4): The intra operative decision making in our study.

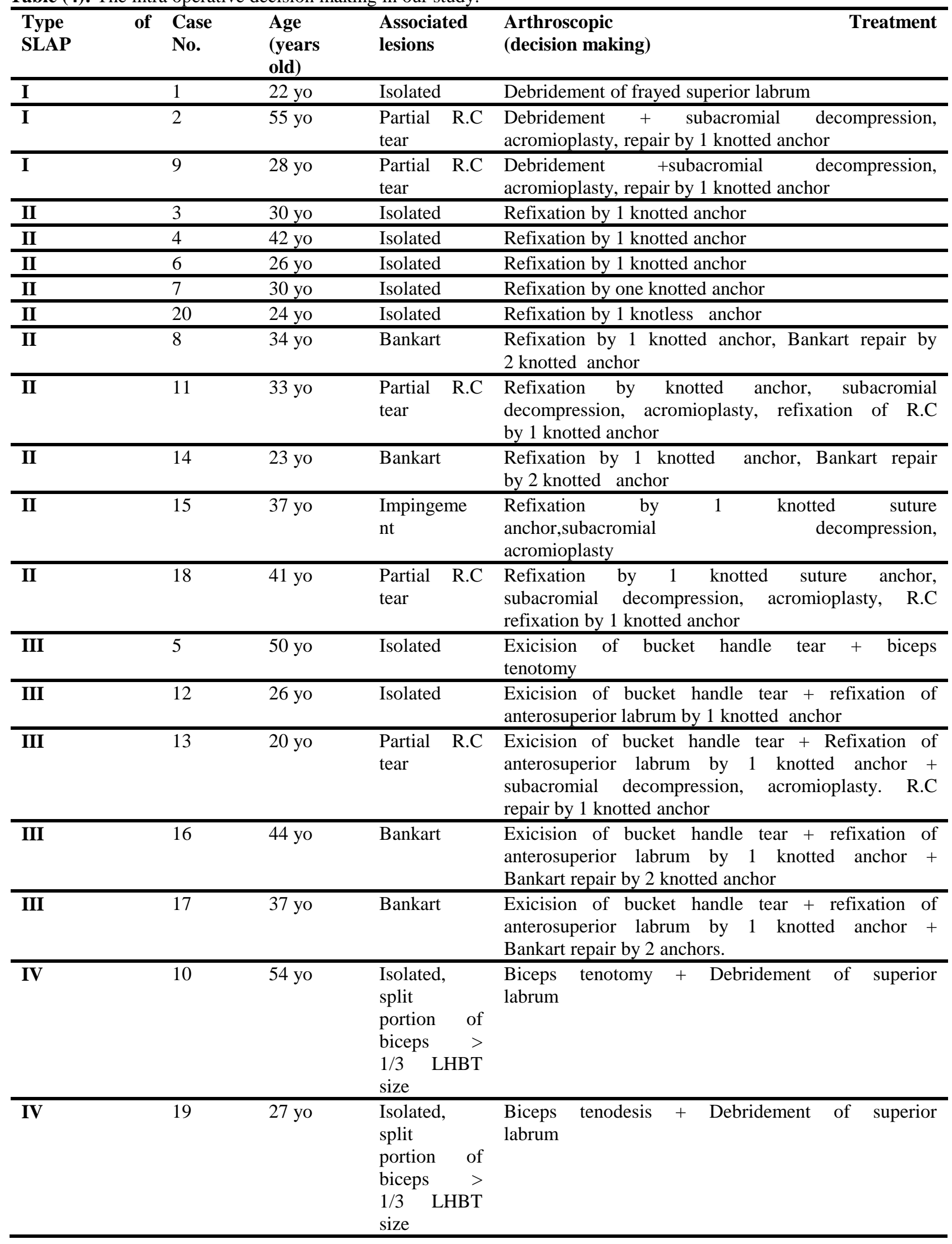



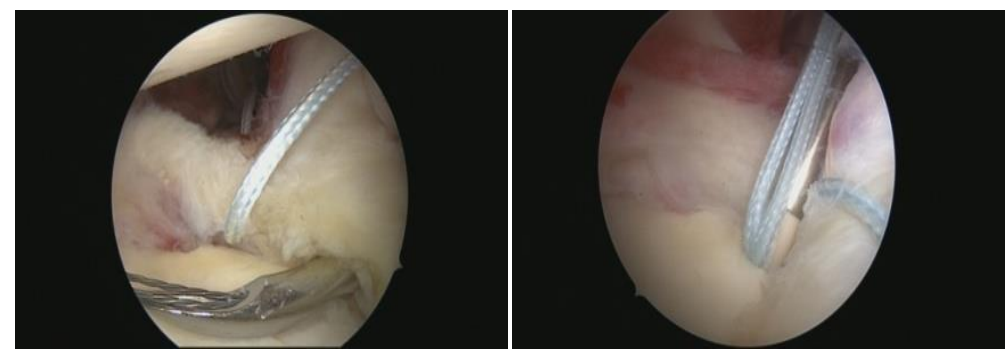

Figure (6): Arthroscopic repair and refixation by knotless suture anchor.
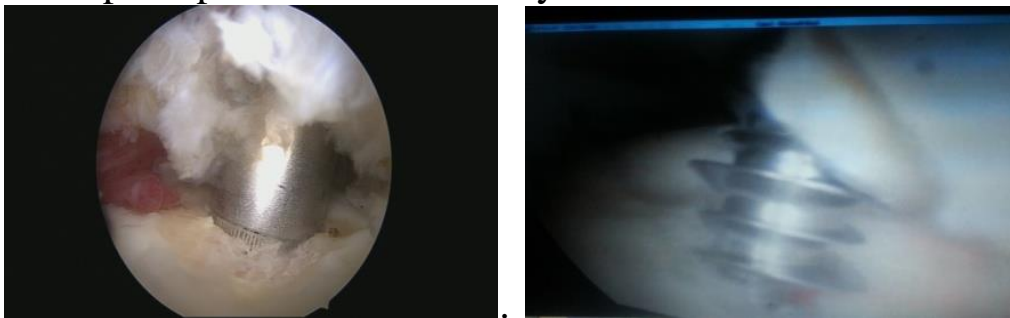

Figure (7): Knotted anchor fixation in upper ant part of humeral head above begining of bicipital groove. Right shoulder, post portal, beech chair.

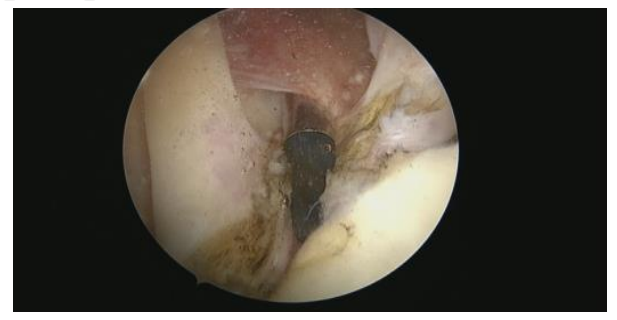

Figure (8): Cutting of LHB (tenotomy).

\section{Post Operative Rehabilitation:}

The patient was seen from the second day of operation and we examine the shoulder surgical wounds, movement of hand and fingers, then we did dressing for the wound once weekly and the sutures were removed after 15 days from operation. Then during the first 3 months after removal of the sutures, the patients regularly examined by us in outpatient clinic in Zagazig university hospitals and ensure that the instructions for physiotherapy were followed by both the physiotherapist and the patients. Then during the next 3 months, the patients were regularly examined every month till the end of 6 months from time of surgery. Then during the next 6 months, the patients were regularly examined by us every 2 months till end of one year from time of surgery, and we did assessment for all patients at 1 year post operative according UCLA score.

- Rehabilitation after Arthroscopic Debridement and Tenotomy:

There was one case with isolated SLAP type I that treated by debridement of the superior labrum and one case with isolated SLAP type III that treated by excision of bucket handle tear and biceps tenotomy and one case with isolated SLAP lesion type IV that treated by biceps tenotomy and debridement of the superior labrum. All these three cases follow the same instructions which were no restriction of shoulder movement and starting early and complete range of motion from second day of the operation for isolated SLAP lesions.

- Rehabilitation Protocol Following Arthroscopic Biceps Tenodesis:

There was one case that underwent biceps tenodesis (patient had isolated SLAP type IV and he was young age 27 years old). The following instructions were followed with the patient during physiotherapy.

During the first 6 weeks: immobilization in a sling and during this period allows active range of motion of the elbow and the wrist, and allows passive external rotation of the shoulder in adduction only. From 6 to 12 weeks: allow active range of motion of the shoulder and avoid lateral abduction, and start 
stretching exercises by allowing forward flexion, internal rotation, external rotation. From $12^{\text {th }}$ week: allow strengthening exercises of the deltoid, biceps, triceps, rotator cuff, scapular stabilizers. From $6^{\text {th }}$ month: allow normal activities ${ }^{[7]}$.

- Rehabilitation Protocol after SLAP Lesion Repair:

Repair and refixation of the torn superior labrum was done in 14 cases, 10 cases were had SLAP type II (5 isolated and 5 associated) and 4 cases were had SLAP type III (one isolated and 3 associated). We followed the following instructions with him during physiotherapy and we sent copy for physiotherapist for these instructions. There were 2 cases with SLAP type I with partial rotator cuff tear that repaired by anchor fixation and they followed the same instructions below.

The first 2 to 3 weeks postoperatively, the patient's shoulder is immobilized in internal rotation in a sling. During that time, prohibits any external rotation and limit abduction to $60^{\circ}$. Pendulum and elbow range-of-motion exercise are encouraged. At 4 weeks, shoulder motion is increased using active-assisted and passive techniques. At this point, the sling is discontinued but we still limit external rotation to $30^{\circ}$ to minimize strain on the labrum through the peel-back mechanism. Over the ensuing 4 weeks, internal rotation and external rotation range of motion activities are progressed to $90^{\circ}$ of shoulder abduction. At approximately 8 weeks, initiation of resistance exercises, with a focus on scapular strengthening, provided adequate motion has been achieved (approximately $115^{\circ}$ to $120^{\circ}$ of shoulder external rotation). No resisted biceps activity (elbow flexion and forearm supination) is allowed for the first 2 months to protect the healing of the biceps anchor. After 4 months, a sport-directed throwing program is initiated in overhead athletes, and contact sports are generally allowed after 6 months ${ }^{[4]}$.

\section{ASSESSMENT:}

Outcome measures consisted of University of California at Los Angeles (UCLA) scores, clinical assessment of range of motion at 1 after surgery. The UCLA score (table 5) assesses pain, function, active forward elevation, strength of forward motion, and patient satisfaction with a maximum score of 35 so, function and reaction are measured. Statistical analysis of the data was performed by the Student $t$ test with significance set at $P<.05$.

Table (5): The UCLA score assesses pain, function, active forward elevation, strength of forward flexion, and patient satisfaction with a maximum score of $35^{[8]}$.

\begin{tabular}{lll}
\hline Item & Description & Score \\
\hline Pain & Always present and severe, strong analgesics frequently & $\mathbf{0}$ \\
\cline { 2 - 3 } & Always present but bearable, strong analgesics occasionally & $\mathbf{2}$ \\
\cline { 2 - 3 } & No or little pain at rest, present during light activities & $\mathbf{6}$ \\
\cline { 2 - 3 } & Present during heavy or particular activities only & $\mathbf{8}$ \\
\cline { 2 - 3 } & Occasional and slight & $\mathbf{1 0}$ \\
\cline { 2 - 3 } & No & $\mathbf{0}$ \\
\hline Function & Can not use the limb & $\mathbf{4}$ \\
\cline { 2 - 3 } & Light activities only are possible & $\mathbf{6}$ \\
\cline { 2 - 3 } & Able to do light housework or most activities of daily living & $\mathbf{1 0}$ \\
\cline { 2 - 3 } & Most housework, shopping, and driving are possible, able to do hair and & $\mathbf{6}$ \\
\cline { 2 - 3 } & to dress and undress, including fastening bra & \\
\cline { 2 - 3 } & Slight restriction only, able to work above shoulder level & $\mathbf{6}$ \\
\cline { 2 - 3 } & Normal activities
\end{tabular}




\begin{tabular}{|c|c|c|}
\hline \multirow{6}{*}{$\begin{array}{l}\text { Active } \\
\text { forward } \\
\text { flexion }\end{array}$} & $<30^{\circ}$ & $\mathbf{0}$ \\
\hline & $30^{\circ}-45^{\circ}$ & 1 \\
\hline & $45^{\circ}-90^{\circ}$ & 2 \\
\hline & $90^{\circ}-120^{\circ}$ & 3 \\
\hline & $120^{\circ}-150^{\circ}$ & 4 \\
\hline & $>150^{\circ}$ & 5 \\
\hline \multirow{6}{*}{$\begin{array}{l}\text { Strength of } \\
\text { forward } \\
\text { flexion } \\
\text { (manual } \\
\text { muscle } \\
\text { testing) }\end{array}$} & Grade 0 (nothing) & $\mathbf{0}$ \\
\hline & Grade 1 (muscle concentration) & 1 \\
\hline & Grade 2 (poor) & 2 \\
\hline & Grade 3 (fair) & 3 \\
\hline & Grade 4 (good) & 4 \\
\hline & Grade 5 (normal) & 5 \\
\hline \multirow{2}{*}{$\begin{array}{l}\text { Patient } \\
\text { satisfaction }\end{array}$} & Not satisfied and worse & $\mathbf{0}$ \\
\hline & Satisfied and better & 5 \\
\hline
\end{tabular}

Interpreting the UCLA Shoulder rating scale: if it is (>27) it means Good to Excellent results and if it is $(<27)$ it means Fair to Poor results. The maximum score is 35 points. Excellent to good means satisfactory results, where as fair to poor indicates unsatisfactory results.

RESULTS

The following Pie diagram shows the distribution of SLAP lesions types in our study (Figure 9).

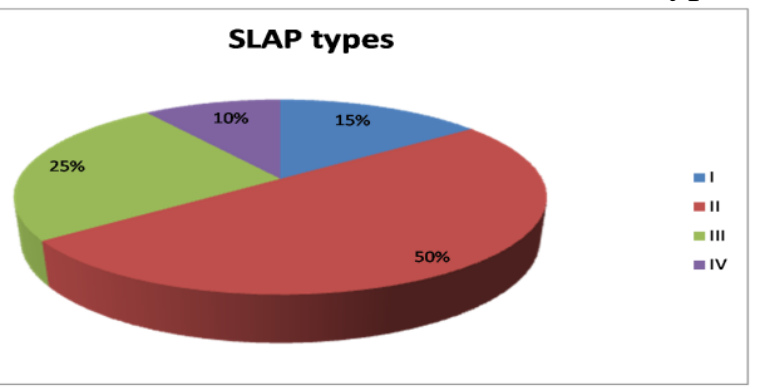

Figure (9): This diagram shows that SLAP type I was 15\%, type II was 50\%, type III was $25 \%$ and type VI was $10 \%$. While the functional outcome following arthroscopic intervention in the isolated SLAP lesions were measured using the University of California at Los Angeles Shoulder Rating scale (UCLA scale).

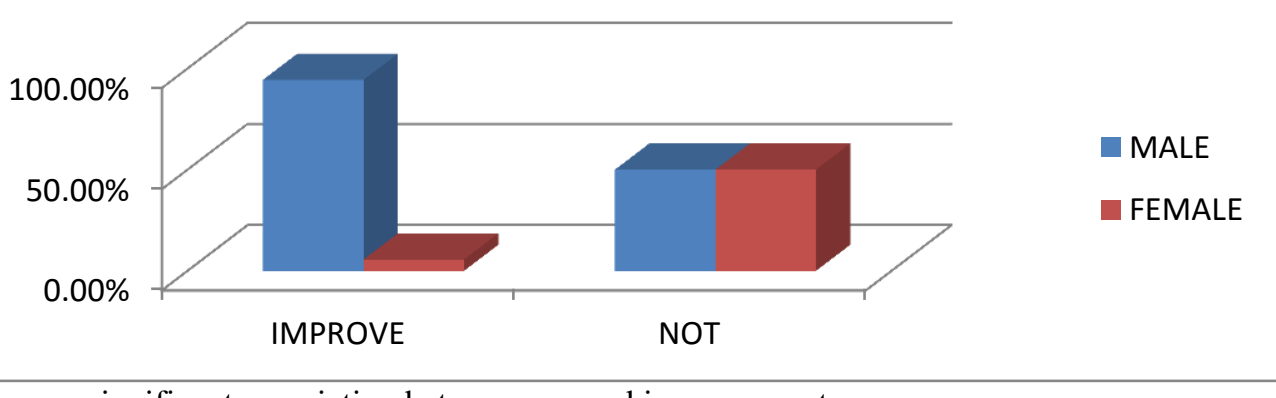

Figure (10): There was significant association between sex and improvement. 
Table (6): This table shows that there was significant difference regarding UCLA score between pre and post operative as in preoperative $100 \%$ UCLA score was <27 Fair/Poor not satisfied, while in postoperative 90\% UCLA score was > 27 Good/Excellent was satisfied, and only 10\% UCLA was < 27 Fair/Poor not satisfied.

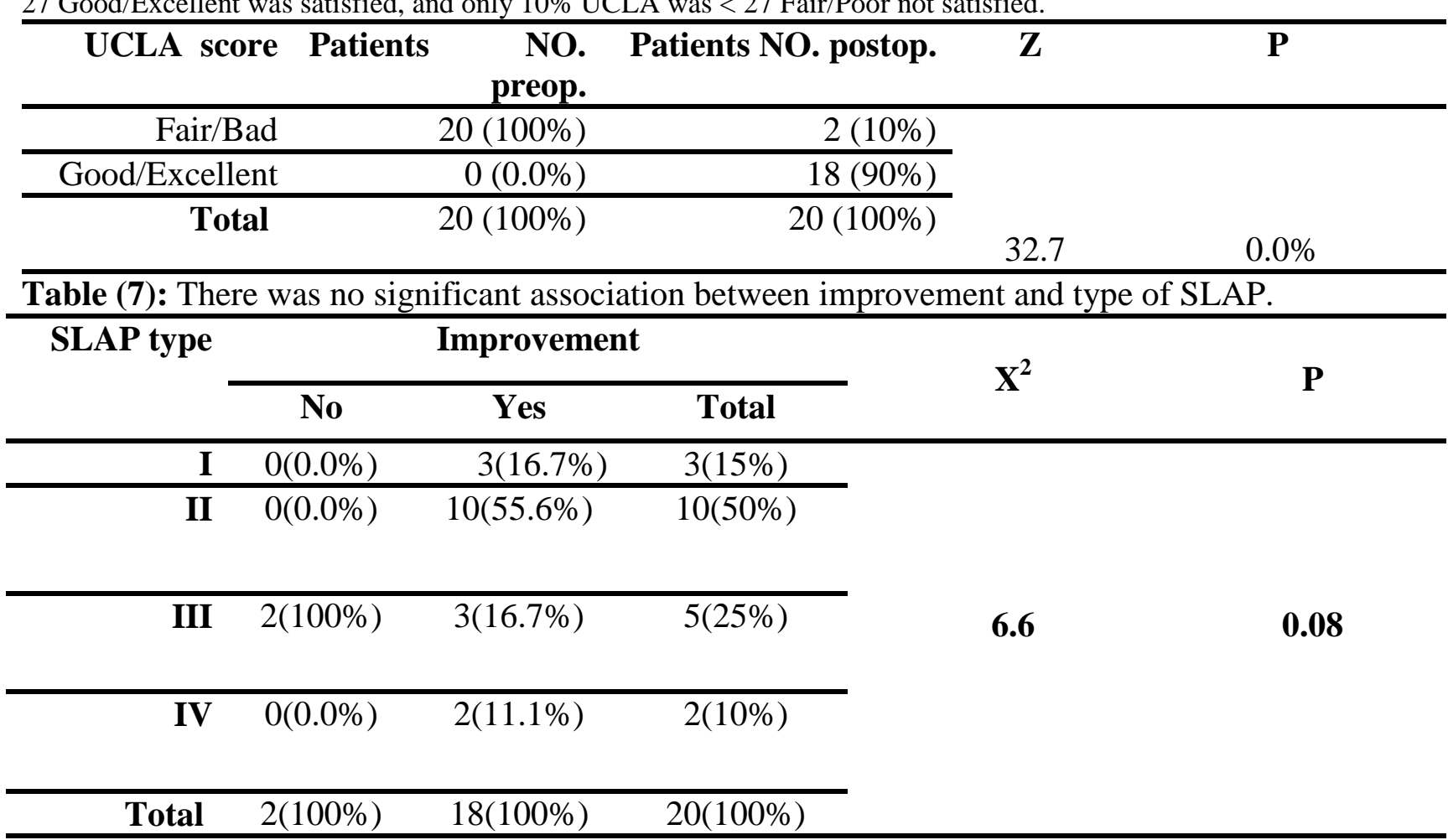

\section{Operative pitfalls and complications:}

During this work, there were some difficulties during arthroscopy, especially in early cases (operative pitfalls):

- In one case, there was difficulty in superior labrum fixation as the patient was obese with narrow shoulder joint space and this made the operation duration longer with extravasation of the shoulder that relieved post operatively without complications.

- In one case, premature cut of the suture was done during knot pushing by knot pusher, so we used another anchor beside this failed anchor.

- In one case, the suture was slipped from anchor itself (iatrogenic) as we passed the suture from the labral tissue but exit from anchor itself so we used another anchor beside this failed anchor.

There were no post operative complications in this study of 20 patients. However, 2 patients (No. 8 and 16, Table 1) reported higher postoperative disability scores. Both of the patients had Type 2 SLAP lesions with associated Bankart lesions. Both lesions were repaired arthroscopically during the same operative session. Postoperatively, the patients reported higher disability scores due to a sensation of instability without frank dislocation. A postoperative magnetic resonance imaging (MRI) reported healed Bankart and SLAP lesions. The patients were managed non operatively with intensive physiotherapy.

\section{DISCUSSION}

This study aimed to evaluate the functional outcome following arthroscopic intervention in the isolated SLAP lesion and associated lesions. The distribution of types of SLAP lesions was, SLAP type I (15\%), type II (50\%), type III (25\%) and type VI (10\%). Type II lesions (50\%) were the most common. This was similarly reported by Synder et al., (1990) [9] was (41\%), Bencardino et al., (2000) (10) was (47\%), Jee et al., (2001) ${ }^{[11]}$ was $(88 \%)$ and Lim et al., (2008) ${ }^{[12]}$.

As the arthroscopic equipment and the understanding of SLAP lesions continue to evolve, more effective surgical treatment modalities are possibly emerging [13, 15]. Clinical results of arthroscopic stabilization of SLAP lesions with suture anchors show success rates ranging from 71 to $97 \%{ }^{[15]}$. While some authors of late favor tenodesis rather than SLAP repair in some situations 
$(16,17)$. In this study, repair of superior labrum was prefered and arthroscpic repair and refixation to the superior labrum was done in 14 cases and only 2 patients (No. 8 and 16, Table 1) reported higher postoperative disability scores. Both of the patients had Type II SLAP lesions with associated Bankart lesions. Both lesions were repaired arthroscopically during the same operative session while the remaining 12 patients that were repaired arthroscopically reported postoperative improvement according to UCLA score.

The indications for biceps tenodesis or tenotomy were in the following conditions:

1) A tear of the tendon involving more than $50 \%$ of its width.

2) Medial sublaxation of the long head.

3) An unstable superior labrum in old age patient more than 50 years as repair with successful healing is doubtful in old age.

Biceps tenodesis was done in the following conditions:

a) Young age less than 50 years.

b) High demand and active (labours \& athletes).

c) Cosmetic concerning.

d) Thin and normal arm size

Biceps tenodesis was done in 1 case where the patient had isolated SLAP type IV and was active and young age (27 years old). The patient postoperative UCLA score was changed from 10 to 30 which indicates good to excellent results.

While biceps tenotomy was done in the following conditions:

a) Old age larger than 50 years.

b) Low demand sedentary life.

c) Cosmetic tolerance.

d) Fat and obese arm size.

Biceps tenotomy was done in 2 cases, both patients were old age (50 and 54 years old), one of them had isolated SLAP type III and the other had isolated SLAP type IV. Both patients postoperative UCLA score was changed from fair into good to excellent results.

Assessment of the results of this study was done according to University of California at Los Angeles (UCLA) scores, and clinical assessment of range of motion at 1 year after surgery. UCLA score was preferred as it assesses pain, function, active forward elevation, strength of forward motion, and patient satisfaction with a maximum score of 35 , so it is subjective and objective score depending on both patient satisfaction and doctor assessment [13]. Statistical analysis of the data was performed by the Student $t$ test with significance set at $P$ $<.05$.

In this study, the preoperative assessment was all cases had their UCLA score less than (27) ranging from (8 to 20) which indicates that the patients were not satisfied and indicated for surgery, while the postoperative assessment 18 cases $(90 \%$ of the cases) had their UCLA score more than (27) ranging from (28 to 33) which indicates good to excellent results and patients were satisfied, and only 2 cases (10\% of the cases) had their UCLA score was less than (27) one was (18) and the other was (20) which indicate fair/poor results and patient were not satisfied. There were high significant differences between pre and post operative results by paired t test regard all parameters pain, function, active forward flexion, strength of forward flexion, satisfaction and UCLA score. Regarding pain, the standard deviation was 1.51831 preoperative that became 1.02084 postoperatively with $\mathrm{p}$ value was 0.00 which indicates highly significant difference. Regarding function, the standard deviation was 1.37267 preoperative that became 1.20961 postoperatively with $\mathrm{p}$ value was 0.00 which indicates highly significant difference. Regarding active forward flexion, the standard deviation was 0.68633 preoperative that became 0.59824 postoperatively with $\mathrm{p}$ value was 0.00 which indicates highly significant difference. Regarding strength of forward flexion, the standard deviation was 0.60481 preoperative that became 0.55012 postoperatively with $\mathrm{p}$ value was 0.00 which indicates highly significant difference. Regarding patients satisfaction, the standard deviation was 0.00000 preoperative that became 1.53897 postoperatively with $\mathrm{p}$ value was 0.00 which indicates highly significant difference. Regarding UCLA score, the standard deviation was 3.49285 preoperative that became 3.85630 postoperatively with $\mathrm{p}$ value 
was 0.00 which indicates highly significant difference.

The various reports thus far have focused on the management outcome of isolated SLAP lesions without associated Bankart lesions. Rhee et al., (2005) [18] reported similar results in their review of arthroscopic intervention of 44 unstable SLAP lesions. $86 \%$ of their patients had good or excellent UCLA scores while, $14 \%$ of their patients had fair or poor UCLA scores. Samani et al., (2001) ${ }^{[19]}$ also reported an overall success rate of $88 \%$ with 23 of 25 cases returning to their pre-injury level of sports participation following arthroscopic treatment. Morgan et al., (1998) ${ }^{[20]}$ reported at 1-year follow-up of 102 repairs of Type 2 lesions that the clinical results assessed by the UCLA score were excellent in $85(83 \%)$ patients, good in 14 patients $(14 \%)$ good, fair in 3 patients $(3 \%)$ and there were no poor results. Lim et al., (2008) ${ }^{[11]}$ reported that $63 \%$ of the patients with isolated lesions showing significant improvement in their postoperative disability score. In this study, (90\%) of the patients with isolated lesions showing significant improvement in their postoperative UCLA score with returning to their pre-injury level of activity participation following arthroscopic treatment.

However, studies on the management of associated Bankart and SLAP lesions are limited. Lim et al, (2008) ${ }^{[11]}$ reported that $73 \%$ of patients with associated lesions had improvement in the postoperative disability score. This outcome supports the recommendation that SLAP and concomitant lesions should be managed in the same operative session. In this study, $90 \%$ of patients with associated lesions had improvement in the postoperative UCLA score. This outcome supports the recommendation that SLAP and concomitant lesions should be managed in the same operative session.

\section{CONCLUSION}

- The criteria for diagnosis of SLAP lesions are history of positive overuse or trauma, pain or click in the superior shoulder area, active compression test or compression rotation test are positive and MRI findings are positive.
The operation was done when the patients fulfilled at least three items.

- The decision making for arthroscopic treatment of SLAP lesion depends on type of SLAP lesion, age of the patient, activity of the patient, associated lesions.

- For diagnosis of SLAP lesions, you should have high index of suspicious, as the most accurate diagnostic tool is by arthroscopy.

- Any patient with shoulder pain or instability, you should consider SLAP lesion until proved otherwise.

- The best treatment of SLAP lesions is to restore the anatomy as near as possible.

- Post operative rehabilitation ranging from starting early and complete range of motion from second day of the operation following arthroscopic debridement or biceps tenotomy to sling immobilization for 6 weeks following SLAP repair or biceps tenodesis.

- Arthroscopic management of SLAP lesions provides good and improved functional outcome while, Conservative management of SLAP lesions is often unsuccessful, particularly when there is a component of glenohumeral joint instability or when a concomitant rotator cuff tear is present.

\section{REFERENCES}

1. Silberberg JM, Moya-Angeler J, Martín E, Leyes $M$ and Forriol F: Vertical versus Horizontal Suture Configuration for the Repair of Isolated Type II SLAP Lesion through a Single Anterior Portal: A Randomized Controlled Trial. Arthroscopy; 2011;27: 1605-1613.

2. Dodson CC and Altchek DW: SLAP Lesions: An Update on Recognition and Treatment. J Orthop Sports Phys Ther; 39:71-80.

3. Keener JD and Brophy RH 2009; Superior Labral Tears of the Shoulder: Pathogenesis, Evaluation, and Treatment. J Am Acad Orthop Surg 2009; 17: 627-637.

4. Mihata T, McGarry MH, Tibone JE, Fitzpatrick MJ, Kinoshita M, and Lee TQ: Biomechanical assessment of type II superior labral anterior-posterior (SLAP) lesions associated with anterior shoulder capsular laxity as seen in throwers: A cadaveric study. Am J Sports Med; 2008;36: 1604-1610.

5. Bedi A and Allen AA: Superior Labral Lesions Anterior to Posterior Evaluation and Arthroscopic Management. Clin Sports Med 2008;27: 607-630.

6. Waterman BR, Cameron $\mathrm{KL}$, Hsiao $M$, Langston JR, Clark NJand Owens BD: Trends in the diagnosis of SLAP lesions in the US 
military. Knee Surg Sports. Traumatol Arthrosc; 2013;37: 22-28.

7. Burkhart SS and Morgan C: SLAP lesions in the overhead athlete. Orthop Clin North Am; 2001;32: 431-441.

8. Kirkley A, Griffin $S$ and Dainty K: Scoring Systems for the Functional Assessment of the Shoulder; Arthroscopy Association of North America; 2003;1109-1120.

9. Snyder SJ, Karzel RP, Del Pizzo W, Ferkel RD and Friedman MJ,: SLAP lesions of the shoulder. Arthroscopy; 1990;6: 274-279.

10. Bencardino JT, Beltran J, Rosenberg ZS, Rokito A, Schmahmann S, Mota J, Mellado JM, Zuckerman J, Cuomo F, and Rose D: Superior labrum anterior-posterior lesions: diagnosis with MR arthrography of the shoulder. Radiology; 2000;214: 267-271.

11. Lim MH, Chan BK and Ooi Low C: Arthroscopic Management of Superior Labral Anterior and Posterior (SLAP) and Associated Lesions: Clinical Features and Functional Outcome. Ann Acad Med Singapore; 2008;37: 44-48.

12. Jee WH, McCauley TR, Katz LD, Matheny JM, Ruwe PA and Daigneault JP,: Superior labral anterior posterior (SLAP) lesions of the glenoid labrum: reliability and accuracy of MR arthrography for diagnosis. Radiology; 2001;218: 127-132.

13. Huri G, Hyun YS, Garbis NG and McFarland EG,: Treatment of superior labrum anterior posterior lesions: a literature review Acta Orthop Traumatol Turc; 2014;48: 290-297.

14. Burkhart SS, Morgan CD and Kibler WB: Shoulder injuries in overhead athletes. The "dead arm" revisited. Clin Sports Med; 2000;19: 125158.

15. Nam EK and Snyder SJ: The diagnosis and treatment of superior labrum anterior and posterior (SLAP) lesions. Am J Sports Med; 2003;31: 798-810.

16. Boileau $P$ and Neyton L: Arthroscopic tenodesis for lesions of the long head of the biceps. Oper Orthop Traumatol 2005; 17:601-623.

17. Boileau P, Baque F, Valerio L, Ahrens P, Chuinard C, Trojani C,: Isolated arthroscopic biceps tenotomy or tenodesis improves symptoms in patients with massive irreparable rotator cuff tears. J Bone Joint Surg Am 2007;89:747-757.

18. Rhee YG, Lee DH and Lim CT: Unstable isolated SLAP lesion: clinical presentation and outcome of arthroscopic fixation. Arthroscopy; 2005;21: 1099.

19. Samani JE, Marston SB and Buss DD: Arthroscopic stabilization of type II SLAP lesions using an absorbable tack. Arthroscopy; 2001;17: 19-24.

20. Morgan CD, Burkhart SS, Palmeri $M$ and Gillespie M,: Type II SLAP lesions: Three subtypes and their relationships to superior instability and rotator cuff tears. Arthroscopy; 1998; 14: 553-565. 